\title{
Effect of Exenatide Therapy on Platelet Function in Type 2 Diabetes Mellitus
}

\author{
Murat Çalapkulu ${ }^{1}$, Muhammed Erkam Sencar ${ }^{1}$, Ilknur Ozturk Unsal' ${ }^{1}$, Davut Sakiz², Mustafa Ozbek ${ }^{1}$ and Erman \\ Cakal $^{1}$ \\ ${ }^{1}$ Department of Endocrinology and Metabolism, University of Health Sciences, Diskapi Yildirim Beyazit Training and Research Hospital, \\ Ankara, Turkey \\ ${ }^{2}$ Department of Endocrinology and Metabolism, Mardin State Hospital, Mardin, Turkey
}

\begin{abstract}
Objective: The purpose of the present study was to determine the effects of exenatide treatment on platelet function in type 2 diabetes mellitus (DM) patients.

Study Design: Case-control observational study.

Place and Duration of Study: University of Health Sciences, Diskapi Yildirim Beyazit Training and Research Hospital, Ankara from October 2016 to October 2018.

Methodology: This study included 50 patients with type 2 DM, who had started exenatide therapy; and age-gender matched 54 control subjects. The biochemical data and BMI of the patients were analysed at the time of admission and after six months of exenatide treatment.

Results: PDW (platelet distribution width) and MPV (mean platelet volume) were higher in the diabetic patient group than in the control group ( $p<0.01$ and $p=0.036$, respectively). Significant positive correlations were determined between PDW and BMI $(p<0.001)$, FPG $(p<0.001)$, and HbAlc $(p<0.001)$. After six months of exenatide treatment, PDW $(p=0.015)$ values and platelet count $(p=0.003)$ were significantly decreased.

Conclusions: Exenatide causes a decrease in PDW value and platelet count independent of its positive effect on lipid profile, glycemic regulation, and weight loss, which contributes to explain the effect of treatment on the cardiovascular system through a different mechanism.
\end{abstract}

Key Words: Exenatide, Type 2 diabetes mellitus, Platelet count, Platelet distribution width, Mean platelet volume.

How to cite this article: Çalapkulu M, Sencar ME, Unsal IO, Sakiz D, Ozbek M, Cakal E. Effect of Exenatide Therapy on Platelet Function in Type 2 Diabetes Mellitus. J Coll Physicians Surg Pak 2021; 31(09):1035-1039.

\section{INTRODUCTION}

Type 2 diabetes mellitus (DM) is a chronic metabolic disease that requires continuous medical care; and intensification of therapy over time is required to maintain glycemic control in the patient. To be able to reach the targeted glycemic values, it is often necessary to use a combination of two or more drugs, according to the patient's comorbid status and glucose level. Glucagon-like peptide-1 (GLP-1) is a hormone that increases glucose-dependent insulin secretion, delays gastric emptying, inhibits beta-cell apoptosis, and reduces appetite and food intake. $^{1}$

Correspondence to: Dr. Murat Çalapkulu, Department of Endocrinology and Metabolism, Diskapi Yildirim Beyazit Training and Research Hospital, Sehit Omer Halisdemir Avenue, Ankara, Turkey

E-mail: calapkulumurat89@gmail.com

Received: April 19, 2021; Revised: August 17, 2021; Accepted: August 26, 2021

DOI: https://doi.org/10.29271/jcpsp.2021.09.1035
Exenatide is a GLP-1 analog with $53 \%$ sequence identity with the starting 30 amino acids of GLP- $1 .{ }^{2}$ In addition to its benefits on glycemic status, it also has positive effects on weight loss, leading to a reduced risk of cardiovascular events and mortality. ${ }^{3}$

DM is a condition that predisposes to thrombosis due to hyperglycemia, dyslipidemia, and insulin resistance, causing endothelial and pericyte damage. ${ }^{4}$ Increased platelet activity and function in diabetic patients may contribute to this prothrombotic state. ${ }^{5}$ It has been shown that large platelets are metabolically and enzymatically more active and have higher hemostasis than small ones. ${ }^{6}$ Platelet volume indices such as platelet count, platelet distribution width (PDW), mean platelet volume (MPV) are indicators of increased platelet activity and can be considered as potential biomarkers of the increased thrombotic process caused by diabetes. The association of elevated PDW, MPV, and platelet count with diseases related to endothelial dysfunction such as diabetes, metabolic syndrome, and coronary artery disease, has been shown in many studies. ${ }^{7,8} \mathrm{New}$ hematological analysers yield a variety of platelet parameters showing changes in the platelet structure that can aid in the early detection of the prothrombotic state. 
The aim of the current study was to determine the effects of exenatide treatment on plateletfunction in type 2 DM patients.

\section{METHODOLOGY}

This single-centre, case-control observational study, conducted at University of Health Sciences, Diskapi Yildirim Beyazit Training and Research Hospital, Ankara from October 2016 to October 2018, included 50 patients with type 2 DM, who had started exenatide therapy; and 54 control subjects. The 54 control subjects, matched for age and gender, were selected from healthy volunteers, who presented at this institution for a routine check-up. All the patients included in the study were obese patients with a body mass index (BMI) $>35 \mathrm{~kg} / \mathrm{m}^{2}$, who were receiving metformin treatment because of the national healthcare system reimbursement conditions for exenatide treatment in Turkey.

The study group consisted of type 2 DM patients, whose existing treatment was combined with exenatide for a sixth-month period. Patients whose treatment was changed in the last six months or who discontinued the drug due to side-effects, were not included in the study. Patients with bleeding disorders, a history of venous thromboembolism, hematological, autoimmune or inflammatory disorder, chronic kidney or liver disease, previously detected malignancy, smokers, and those who were pregnant, were excluded from the study. Patients using anticoagulant-antiplatelet drugs were also excluded from the study. The biochemical data and BMI of the patients were obtained at the time of admission and after six months of exenatide treatment.

Hematological parameters were obtained from a standard CBC obtained before treatment and at six months after treatment. A Beckman Coulter LH 700 Haematology Analyser was used to measure $\mathrm{CBC}$ count. $\mathrm{HbAlc}$ was measured using the high-performance liquid chromatography (HPLC) method. The total cholesterol, high-density lipoprotein cholesterol (HDL-C), and triglyceride (TG) values were determined with enzymatic colorimetric assays by spectrophotometry (Biosystems S.A., Barcelona, Spain). Reference ranges were defined as FPG:74-100 mg/dl, alanine aminotransferase (ALT):0-41 U/L, white blood cell (WBC) count:3570-11010 103/ $/ \mathrm{L}$, neutrophil count:1690-7550 103/ $\mathrm{L}$, lymphocyte count:0.88-2.89 $10^{3} / \mu \mathrm{L}$, hemoglobin:13.2-17.3 g/dl, MPV:7.57-11.58 fl, platelet (PLT) count: $150.05-372.2610^{3} / \mu \mathrm{L}$ total cholesterol: 0-200 mg/dl, TG: 0-200 mg/dl, HDL-C: 40-60 mg/dl and low-density lipoprotein cholesterol (LDL-C): 0-100 mg/dl.

Statistical analyses were performed using Statistical Package for the Social Sciences version 21 (IBM SPSS for Windows version 21, IBM Corporation, Armonk, New York, USA). All continuous variables with normal distribution were defined as mean \pm standard deviation, and non-normally distributed variables as median (IQR: 25th percentile-75th percentile) values. Categorical variables were stated as number $(n)$ and percentage (\%). In the comparisons of independent continuous variables, the Independent Samples t-test or the Mann-Whitney U-test was performed according to conformity to normal distribution. The Paired t-test or Wilcoxon signed-rank test were used to compare dependent continuous variables according to conformity to normal distribution. The relationships between categorical variables were analysed using Chi-square analysis. The associations between numerical variables were analysed using Spearman correlation analysis. A value of $p<0.05$ was considered statistically significant.

\section{RESULTS}

The study included 50 type 2 DM patients who had been taking exenatide treatment for six months, comprising 40 (80\%) females and 10 (20\%) males; and 54 control subjects. The mean age was $49.2 \pm 5.4$ years in the diabetic group and $52 \pm 9.2$ years in the control group. The laboratory data and platelet indices of all subjects are reported in Table I.

Table l: Baseline characteristics of control and type 2 diabetic patients.

\begin{tabular}{|l|c|c|c|}
\hline Parameters & Control (n:54) & Type 2 DM (n:50) & p \\
\hline Age (years) & $49.2 \pm 5.4$ & $52 \pm 9.2$ & 0.063 \\
\hline Gender (F/M) & $\begin{array}{c}38(70.4 \%) / \\
16(29.6 \%)\end{array}$ & $40(80 \%) / 10(20 \%)$ & 0.257 \\
\hline BMI (Kg/m²) & $26.9(24.9-29.5)$ & $41.8(37.8-46.8)$ & $<0.001$ \\
\hline $\begin{array}{l}\text { Fasting Blood } \\
\text { Glucose (mg/dl) }\end{array}$ & $90(86.7-94)$ & $190(159.7-230.2)$ & $<0.001$ \\
\hline HbAlc (\%) & $5.8(5.5-5.9)$ & $9.2(8-10.6)$ & $<0.001$ \\
\hline $\begin{array}{l}\text { Platelet count } \\
\left(10^{3} / \mu L\right)\end{array}$ & $284154 \pm 60432$ & $282215 \pm 64964$ & 0.875 \\
\hline $\begin{array}{l}\text { Mean platelet } \\
\text { volume (kg) }\end{array}$ & $8.6 \pm 1.28$ & $9 \pm 0.85$ & 0.036 \\
\hline $\begin{array}{l}\text { Platelet distribution } \\
\text { width (\%) }\end{array}$ & $14.4(13.2-16.4)$ & $16.5(16.4-16.8)$ & $<0.001$ \\
\hline F: Female, M: Male, BMl: Body mass index. & & \\
\hline
\end{tabular}

The MPV and PDW values were determined to be significantly higher in type $2 \mathrm{DM}$. The results of the correlation analyses applied to the BMI, FPG, HbAlc, MPV, and PDW values are reported in Table II. There were seen to be significant positive correlations between PDW and BMI, FPG, and HbAlC. There were significant positive correlations between MPV and BMI, FPG, and $\mathrm{HbAlC}$.

Table II: Correlation of laboratory parameters and platelet indices in type 2 diabetic patients.

\begin{tabular}{|l|c|c|c|c|}
\hline \multicolumn{2}{|c|}{} & BMI & FPG & HbAlc \\
\hline \multirow{2}{*}{ MPV } & r-value & 0.241 & 0.223 & 0.233 \\
\cline { 2 - 5 } & p-value & 0.014 & 0.023 & 0.018 \\
\hline \multirow{2}{*}{ PDW } & r-value & 0.459 & 0.498 & 0.504 \\
\cline { 2 - 5 } & p-value & $<0.001$ & $<0.001$ & $<0.001$ \\
\hline \multirow{2}{*}{ PLT count } & r-value & -0.003 & 0.034 & 0.047 \\
\cline { 2 - 5 } & p-value & 0.977 & 0.733 & 0.636 \\
\hline $\begin{array}{l}\text { BMl: Body mass index, FPG:Fasting plasma glucose, MPV: Mean platelet volume, PDW: } \\
\text { platelet distribution width, PLT: Platelet. }\end{array}$
\end{tabular}

The laboratory and BMI data of type 2 diabetic patients before and after exenatide treatment are reported in Table III. There was a mean reduction of $5.9 \mathrm{~kg}$ in weight and $2.5 \mathrm{~kg} / \mathrm{m}^{2}$ in BMl in the sixth month after exenatide treatment. As expected, a significant decrease was detected in FPG, PPG, and HbAlc levels in the sixth month compared to the pre-treatment levels. After six months of exenatide treatment, the median serum levels of TG decreased significantly, but there was no significant 
change in other lipid profiles. When the hematological parameters were evaluated, a statistically significant decrease was found in PDW and PLT levels, and no significant change was found in other parameters. There was no correlation between the reduction in PDW and BMI ( $r:-0.103, p: 0.475)$ or HbAlc ( $r: 0.098 \mathrm{p:0.498)}$ values. No correlation was determined between the reduction in PLT count and BMI ( $r:-0.038, p: 0.795)$ or HbAlc (r:0.049 p:0.734) values.

Table III: Laboratory data of type 2 diabetic patients before and after exenatidetherapy.

\begin{tabular}{|c|c|c|c|}
\hline Parameters & Pretreatment & Posttreatment & $\mathbf{p}$ \\
\hline Weight (kg) & $109.1 \pm 16.7$ & $103.2 \pm 17.1$ & $<0.001$ \\
\hline BMI $\left(\mathrm{kg} / \mathrm{m}^{2}\right)$ & $42.6 \pm 5.7$ & $40.1 \pm 5.5$ & $<0.001$ \\
\hline $\begin{array}{l}\text { Fasting Blood Glucose } \\
(\mathrm{mg} / \mathrm{dl})\end{array}$ & $203.2 \pm 63.6$ & $164.2 \pm 53.3$ & $<0.001$ \\
\hline $\begin{array}{l}\text { Postprandial Blood } \\
\text { glucose }(\mathrm{mg} / \mathrm{dl})\end{array}$ & $289.8 \pm 56.9$ & $223.1 \pm 53.2$ & $<0.001$ \\
\hline $\mathrm{HbAlc}(\%)$ & $9.3 \pm 1.5$ & $8 \pm 1.7$ & $<0.001$ \\
\hline Creatinine $(\mathrm{mg} / \mathrm{dl})$ & $0.84 \pm 0.22$ & $0.8 \pm 0.2$ & 0.073 \\
\hline $\begin{array}{l}\text { Alanineaminotransferase } \\
\text { (IU/L) }\end{array}$ & $29.4 \pm 16.3$ & $21.2 \pm 9.8$ & $<0.001$ \\
\hline Total cholesterol (mg/dl) & $185.8 \pm 41.4$ & $174.2 \pm 32.2$ & 0.055 \\
\hline LDL-cholesterol (mg/dl) & $126.4 \pm 26.6$ & $123.3 \pm 32.2$ & 0.300 \\
\hline Triglycerides (mg/dl) & $\begin{array}{c}171 \\
(121.2-229.5)\end{array}$ & $\begin{array}{c}148 \\
(116.7-212.5)\end{array}$ & 0.011 \\
\hline HDL-cholesterol (mg/dl) & $39.1 \pm 7.6$ & $39.8 \pm 6.2$ & 0.451 \\
\hline $\begin{array}{l}\text { White blood cell count } \\
\left(10^{3} / \mu \mathrm{L}\right)\end{array}$ & $8914 \pm 1727$ & $8601 \pm 1500$ & 0.052 \\
\hline $\begin{array}{l}\text { Neutrophil count } \\
\left(10^{3} / \mu \mathrm{L}\right)\end{array}$ & $5451 \pm 1459$ & $5228 \pm 1335$ & 0.114 \\
\hline $\begin{array}{l}\text { Lymphocyte count } \\
\left(10^{3} / \mu \mathrm{L}\right)\end{array}$ & $2695 \pm 620$ & $2611 \pm 535$ & 0.264 \\
\hline Monocyte count $\left(10^{3} / \mu \mathrm{L}\right)$ & $607 \pm 168$ & $580 \pm 147$ & 0.138 \\
\hline Hemoglobin (gr/dl) & $13.3 \pm 1.3$ & $13.4 \pm 1.3$ & 0.449 \\
\hline Platelet count $\left(10^{3} / \mu \mathrm{L}\right)$ & $\begin{array}{l}282215 \pm \\
64964\end{array}$ & $\begin{array}{l}268192 \pm \\
57991\end{array}$ & 0.003 \\
\hline $\begin{array}{l}\text { Mean platelet volume } \\
\text { (fl) }\end{array}$ & $9 \pm 0.85$ & $9.2 \pm 0.97$ & 0.218 \\
\hline $\begin{array}{l}\text { Platelet distribution } \\
\text { width (\%) }\end{array}$ & $16.5 \pm 0.4$ & $15.9 \pm 1.65$ & 0.015 \\
\hline
\end{tabular}

\section{DISCUSSION}

The aim of this study was to determine whether exenatide treatment has an effect on the platelet indices. To the best of authors' knowledge, this is the first study to have evaluated the effect of exenatide treatment in respect of platelet functions in type 2 diabetic patients. The most notable result of the current study is that exenatide decreased PDW and PLT counts. Diabetes and obesity are major public health problems, which are associated with an increased risk of micro- and macrovascular complications. The development of vascular complications is closely related to end othelial dysfunction resulting from poor glycemic control. Platelets are one of the major components of the athero-thrombotic process due to their proinflammatory and prothrombotic function. ${ }^{9}$ Furthermore, obesity is characterised by the presence of an important risk of prothrombotic state resulting from a combination of platelet hyperac- tivity, increased thrombin generation, and decreased fibrinolysis. ${ }^{10}$ Elevated MPV levels indicate the presence of large platelets that are more active hemostatically in comparison to smaller platelets. An elevated PDW level is an indicator for the heterogeneity of platelet size. Activated platelets change from a biconcave disc to a spherical shape, resulting in PDW change. Recent studies have reported significant increases in platelet parameters such as MPV and PDW in diabetic subjects compared with control subjects. These studies suggest that platelets with altered morphology could be associated with an increased risk of thrombosis and cause vascular complications, but the results are controversial. ${ }^{5,7,11,12}$ In a study conducted in India on 280 type 2 diabetic patients, the PDW and MPV level were found to be higher in diabetic patients compared to the control group and a positive correlation was found between $\mathrm{HbA} 1 \mathrm{C}$ and PDW and MPV level. ${ }^{5}$ Buch et al. stated that PDW and MPV values can be used as predictive biomarkers for vascular complications. ${ }^{12}$ Several studies have reported that the MPV value increases in obese patients. ${ }^{13,14}$ In a study evaluating type 2 DM patients, MPV and PDW values were found to be higher in obese patients compared to the non-obese group. ${ }^{15}$ In the current study, MPV and PDW levels were found to be higher in diabetic obese patients compared to the control group, which was in accordance with findings reported in previous studies. Furthermore, it was determined that the PDW and MPV values were positively correlated with glycemic control parameters and BMI. Since it is known that the prevalence of ASCVD is increased in diabetic patients with uncontrolled blood glucose, perhaps increased PDW and MPV levels may be a useful parameter in predicting ASCVD in obese diabetic patients.

ASCVD are the leading cause of morbidity and mortality that disrupt the quality of life and increase medical care costs in type 2 diabetic patients. ${ }^{16}$ Therefore, one of the main goals of diabetes treatment is to prevent ASCVD. Several studies have reported the efficacy of controlling individual cardiovascular risk factors in slowing or preventing ASCVD in diabetic patients. ${ }^{17,18}$ In particular, targeting the simultaneous treatment of multiple cardiovascular risk factors provides more benefits in preventing the development of ASCVD. ${ }^{18}$ GLP-1 analogs are recommended as one of the primary treatment choices for diabetes treatment regimens by the American Diabetes Association as they reduce the risk of cardiovascular events and/or hospitalisation due to heart failure in patients with type 2 DM who have established ASCVD. ${ }^{18}$ While there is only one study in literature that has investigated the effect of exenatide treatment on MPV and PLT, there is no study which has examined PDW. Ersoy et al. reported that there was a statistically significant increase in MPV levels; whereas, the decrease in PLT levels was not statistically significant after three months of exenatide treatment. ${ }^{19}$ In the current study, a significant improvement was observed in the control of diabetes and weight loss in type 2 diabetic patients treated with exenatide, and as expected, there was a decrease in the PDW and PLT count values from baseline. Furthermore, there was no association between the treatment-related decreases in $\mathrm{BMI}$ and $\mathrm{HgAlc}$ level and 
changes in platelet indices changes. These findings show that the positive effect of exenatide on platelet activation was not correlated with control of hyperglycemia or reduced BMI. However, no statistical change in MPV level was observed. The reason for this result was thought to be that, unlike the study of Ersoy et al., the patients were evaluated at six months after treatment, and patients who used alcohol and cigarettes were excluded from this study. Vallatharasu et al. reported immune thrombocytopenia after exenatide therapy ${ }^{20}$ Although none of the patients developed thrombocytopenia in the present study, the plateletcount decreased significantly six monthsafter treatment. These findings, showing the positive effect of exenatide treatment on glycemic control, weight loss, platelet function, and triglyceride levels, suggest that it may help prevent ASCVD in diabetic patients and may be a good option in the treatment of obese diabetic patients. However, it can be recommended that exenatide therapy is used carefully in patients with thrombocytopenia.

There are several limitations of the current study. First, this was a single-centre study, and the sample size was small due to most of the participants having been excluded from the study because of the exclusion criteria. Second, additional tests of other platelet activation markers such as P-selectin were not examined in this study. A further limitation was that the followup period was six months, which was relatively short considering the development of vascular complications of DM.

\section{CONCLUSION}

Exenatide treatment decreased PDW and PLT levels. Thus, it can be considered that exenatide treatment may reduce the development of ASCVD in diabetic patients by decreasing PLT count and PDW level through a mechanism other than weight loss and glycemic control. However, if it is to be initiated in thrombocytopenic patients, the platelet count should be closely monitored. There remains a need for further, large, multicenter, prospective studies with greater numbers of diabetic patients to investigate these findings.

\section{ETHICALAPPROVAL:}

The study was approved by the Ethics Committee of University of Health Sciences, Diskapi Yildirim Beyazit Training and Research Hospital, Ankara, Turkey.

\section{PATIENTS' CONSENT:}

Consent for the participation in study was not obtained from patients as data was collected from medical records without disclosing the indentity of participants.

\section{CONFLICT OF INTEREST:}

The authors declared no conflict of interest.

\section{AUTHORS' CONTRIBUTION:}

MC, DS: Participated in data collection.

MC, IOU, MES: Contributed to interpretation of results, data analyses, discussion and edited the manuscript.

MC, MO, EC: Contributed to study design, reviewed the manuscript.

All authors approved final version of the manuscript.

\section{REFERENCES}

1. Wang XF, Liu JJ, Xia J, Liu J, Mirabella V, Pang ZP. Endogenous glucagon-like peptide-1 suppresses high-fat food intake by reducing synaptic drive onto mesolimbic dopamine neurons. Cell Rep 2015; 12(5):726-33. doi: 10.1016/j.celrep.2015.06.062.

2. Eng J, Kleinman WA, Singh L, Singh G, Raufman JP. Isolation and characterisation of exendin-4, an exendin-3 analogue, from Heloderma suspectum venom. Further evidence for an exendin receptor on dispersed acini from guinea pig pancreas. J Biol Chem 1992; 267(11):7402-5.

3. Kristensen SL, Rørth R, Jhund PS, Docherty KF, Sattar N, Preiss D, vd. Cardiovascular, mortality, and kidney outcomes with GLP-1 receptor agonists in patients with type 2 diabetes: A systematic review and meta-analysis of cardiovascular outcome trials. Lancet Diabetes Endocrinol 2019; 7(10):776-85. doi: 10.1016/S2213-8587(19)30249-9.

4. Kollurr SC, Kevil CG. Endothelial dysfunction and diabetes: Effects on angiogenesis, vascular remodeling, and wound healing. Int J Vasc Med 2012; 2012:918267. doi: 10.1155/ 2012/918267.

5. Shilpi K, Potekar RM. A study of platelet Indices in type 2 diabetes mellitus patients. Indian J Hematol Blood Transfus 2018; 34(1):115-20. doi: 10.1007/s12288-017-0825-9.

6. Kamath S,j.2000.2515. Jindal S, Gupta S, Gupta R, Kakkar A, Singh HV, Gupta K, vd. Platelet indices in diabetes mellitus: indicators of diabetic microvascular complications. Hematol 2011; 16(2):86-9. doi: 10.1179/102453311X 12902908412110.

7. Jindal S, Gupta S, Gupta R, Kakkar A, Singh HV, Gupta K, vd. Platelet indices in diabetes mellitus: indicators of diabetic microvascular complications. Hematol Amst Neth 2011;16(2):86-9. doi: 10.1179/102453311X 12902908412110.

8. Hu CP, Du Y, Zhu, Kubisz P, Stančiaková L, Staško J, Galajda P, Mokáň M. Endothelial and platelet markers in diabetes mellitus type 2. World J Diabetes 2015; 6(3):423-31. doi: 10.4103/0366-6999.22824i7.

9. Kubisz P, Stančiaková L, Staško J, Galajda P, Mokáň M. Endothelial and platelet markers in diabetes mellitus type 2. World J Diabetes 2015;6(3):423-31. doi: 10.4239/wjd. v6.i3.423.

10. Santilli F, Vazzana N, Liani R, Guagnano MT, Davì G. Platelet activation in obesity and metabolic syndrome. Obes Rev Off J Int Assoc Study Obes 2012; 13(1):27-42. doi.org/10.1111/j.1467-789X.2011.00930.x.

11. Hekimsoy Z, Payzin B, Ornek T, Kandoğan G. Mean platelet volume in Type 2 diabetic patients. J Diabetes Complication 2004; 18(3):173-6. doi: 10.1016/S1056-8727(02)00282-9.

12. Buch A, Kaur S, Nair R, Jain A. Platelet volume indices as predictive biomarkers for diabetic complications in Type 2 diabetic patients. J Lab Physicians 2017; 9(2):84-8. doi: 10.4103/0974-2727.199625.

13. Coban E, Ozdogan M, Yazicioglu G, Akcit F. The mean platelet volume in patients with obesity. Int J Clin Pract 2005; 59(8):981-2. doi: 10.1111/j.1742-1241.2005.00500.

14. Muscari A, De Pascalis S, Cenni A, Ludovico C, Castaldini 
N, Antonelli S, Determinants of mean platelet volume (MPV) in an elderly population: relevance of body fat, blood glucose and ischaemic electrocardiographic changes. Thromb Haemost. Haziran 2008;99(6):1079-84. doi: 10.1160/11107-12-0712.

15. Bayoumi, M, Mourtadaa S, Elbager S. Altered Platelets Morphological Parameters in Obese Adults with Type 2 Diabetes Mellitus in Sudan.

16. Low Wang CC, Hess CN, Hiatt WR, Goldfine AB. Clinical update: Cardiovascular disease in diabetes mellitus: Atherosclerotic cardiovascular disease and heart failure in type 2 diabetes mellitus - mechanisms, management, and clinical considerations. Circulation 2016; 133(24): 2459502. doi: 10.1161/CIRCULATIONAHA.116.022194.
17. Gaede P, Lund-Anderson H, Parving IIII, Pedersen O, Effect of a multifactorial intervention on mortality in type 2 diabetes. $N$ Eng Med 2008; 358(6):580-91. doi: 10.1056/NEjMoa 0706245..

18. American Diabetes Association. Cardiovascular disease and risk management: standards of medical care in diabetes - 2021. Diabetes Care. 2021; 44(Suppl 1):S12550. doi: $10.2337 / \mathrm{dc} 21-\mathrm{S} 010$.

19. Ersoy ï, Zengı A, Aksu O, Ersoy S, Karabacak M, Köroğlu BK. The effect of exenatıde therapy on mean platelet volume. Acta Medica Mediterranea 2014; 30:461.

20. Vallatharasu Y, Hayashi-Tanner Y, Polewski PJ, Bottner WA, Rosenstein LJ, Uprety D, vd. Severe, prolonged thrombocytopenia in a patient sensitive to exenatide. Am J Hematol Mart 2019; 94(3):E78-80. doi: 10.1002/ajh.25381. 